\title{
Editorial
}

\section{The impact of AIDS on medical ethics}

Anthony J Pinching, Roger Higgs and Kenneth M Boyd St Bartholomew's and The Royal London School of Medicine and Dentistry, London, Guy's, King's and St Thomas'School of Medicine, King's College London and Edinburgh University Medical School and The Institute of Medical Ethics, respectively

\section{Editor's note}

Professor Pinching, Professor Higgs and Dr Boyd are guest editors of this special issue of the journal which is devoted to the subject of medical ethics, AIDS and HIV.

\section{Guest Editors' introduction}

For this special issue of the fournal of Medical Eth$i c s$ we have assembled articles that reflect some of the newer issues or fresh perspectives. There is a mix of approaches including forward looks, present dilemmas and reflections on the past, now that sufficient time has elapsed to allow a considered view. We are most grateful to our wide range of contributors for their thoughtful analyses of several key areas of contemporary debate. Our own contributions include the following editorials in which each of us has considered, from his own perspective, the impact of AIDS on medical ethics, a case study and a lexicon that allows brief probing of some topics.

\section{The impact of aids on medical ethics -1 ANTHONY J PINCHING}

Medical ethics has been matured through being tested and refined through the multifaceted challenge of AIDS. As with the society and social values from which its moral framework is derived, so medical ethics has been subjected to intense scrutiny by the emergence of this new disease. Few areas of ethical discourse have been untouched. This infection is so intensely private in its transmission, the disease so isolating and so personally devastating in its impact, it readily distinguishes the reality of what people are and do, from the rhetoric of what others may feel they should be and do. AIDS has forced us to recognise that respecting individual rights is a critical safeguard for the health of the community, as well as for the person. These issues are well illustrated by the interweaving issues of patient empowerment, respect for confidentiality, and patient advocacy and activism.
EMPOWERMENT

Physicians in this field have been struck by the way in which people affected have wanted to be involved in decision making. While this has often been ascribed to their social groups, it probably was more a reflection of their younger age and a generation change in expectations of health care. While medicine and medical ethics were already moving towards a more explicit recognition of personal autonomy, AIDS has accelerated and catalysed the process. Faced initially with a disease of overwhelming severity that would so shorten their lives, and the limitations of treatment, it is understandable that patients wanted to explore the options and to make the vital choices.

Clinicians could not, even if they had wanted to, hide the grim realities of the early years. Making the best of the situation required a fundamental honesty. What was surprising was how practising medicine, and resolving some of the more tricky dilemmas, became easier if the patient was enabled to make the choices. Thus, where there was genuine uncertainty about treatment, the patient could be enabled to make a choice based on his or her judgment of the risks and benefits. Different patients would make different choices in the same situation, as the medical scenario is not necessarily the critical determinant, but rather the nature and beliefs of the person affected.

Similarly, the stage when active intervention was abandoned for a palliative approach of symptom relief could be navigated with the patient's hand firmly on the tiller. This avoided the inappropriate prolongation of well-meaning attempts to treat. It also helped patients to participate in the recognition that they were approaching death, and thus to prepare and adapt. I still recall the sense of relief as well as of respect, when a patient, with advanced and deteriorating disease, who had travelled the world and achieved all his goals, said smilingly: "It's time to go, Tony". The ultimate choice made by the right person. 
Thus empowerment reduced the burden of decision making, and its associated ethical dilemmas, by returning control to the person to whom it properly belonged. Negotiating the extent to which patients wished to participate and the amount of information they needed to do so, became a crucial part of the dialogue. One option was for patients to ask the clinician to make the decisions on their behalf; that was in itself enabling. Furthermore, it was helpful to offer suggestions, based on knowledge of the individual and his medical situation, and to check the patient was content with them, without imposing the actual choice upon the patient.

Some have argued that truth-telling in grave medical situations can be an imposition, if the patient would have preferred not to know. Yet, many people who had previously declared that they couldn't handle a diagnosis of AIDS, or some particular consequence such as loss of vision or ability to walk, have adapted remarkably to these situations, and retained their wish to live. The extraordinary adaptability of human beings is easily underestimated. Well-meaning partners, friends or family may ask clinicians not to tell patients their diagnosis or prognosis "because they couldn't cope". This would create unnecessary barriers between the patient and the clinician, and the patient and those closest to him, with the burden of concealment and dishonesty; it would also become increasingly hard to sustain.

However, for those patients who really do not want to know, the power of denial is formidable. Patients, who have been unambiguously told their diagnosis and prospects, can present a seemingly impenetrable façade of denial. They may make seemingly inappropriate plans for the future. This can be an important coping mechanism ("positive avoidance") and should not be disrupted. It can be seen as a, perhaps unconscious, choice not to know what they have been told.

As treatments have improved, so the content of the debate between clinician and patient has shifted. Empowerment is now much more focused on maintenance of long term health. Similarly arbitrary choices need to be made, in this case reflecting our uncertainty of how to deploy the available agents. The talk is of virus replication, drug resistance and recoverability of immune damage. Discussions now focus on whether to apply maximal suppression early or to keep options in reserve. We don't have long term data (though there is much strongly expressed opinion!) to show the best approach, and we may not yet have the optimal drugs. Therefore, the patient's philosophy about the approach is the most pertinent. Critically, it will enhance patients' adherence to the very demanding regimes, because they own the decision, and increase acceptance of long term consequences of their choices.

Thus, empowerment has shifted control back to the patient, giving the clinician a more appropriate role as guide and enabler. Negotiating the extent of this empowerment, and the best way of effecting it, requires care and skill. It extends the art of medicine.

\section{CONFIDENTIALITY}

The duty of medical confidentiality is of course well enshrined in the practice of medicine and the expectations of patients. As one of the central expressions of ethical practice it could have been taken as a given. However, HIV has allowed us to confront the difficult tensions that arise in attempting to achieve it in reality.

HIV as a transmissible disease, and above all as one that is transmitted in private, or even clandestine, settings raises issues about duties to protect the public health. Yet those very settings are ones that provoke inappropriate interest in outsiders. The language used illustrates how perceptions vary on the same precept: privacy, confidentiality, concealment, secrecy or cover-up. The groups first affected were ones for which stigma or a perception of being different/"other" raised a particular, if generally unhealthy, interest among the so-called general public. This offered people an opportunity to find out about such people, and yet to distance themselves from the epidemic. When HIV affected people who were in the public eye the view was seemingly taken that, as public figures (for example, artist, politician), they had relinquished their rights to privacy. Whether their lifestyle is of legitimate interest is perhaps moot, but medical confidentiality could not be so easily swept aside.

In the early years, every patient raised issues of interest to the public or, even more, the media, as first examples of various situations. For good reason or ill, relating a case to an identifiable individual was seen to increase the interest. While some were indeed willing to put themselves forward, many others were pushed into the limelight without any choice, and with terrible harm being done do them, their families and friends. The need to provide secure and confidential health care in this context revealed some of the weaknesses in both policies and practice. Boundaries were unthinkingly transgressed, without determining right to know.

Those wishing to probe medical confidentiality exploited weaknesses in a system that depended on assumed codes of practice. Cheques were paid 
to low-paid clerical staff remote from the clinical setting, and some "friends" bringing flowers for patients turned out to be journalists. Calls were made to junior doctors or night nurses for patient information. It was notable that the legal proceedings to protect confidentiality of individuals with HIV from media exposure were the first case law on medical confidentiality in the UK ("X v Y").

On the other hand, relevant information was sometimes, needlessly and inappropriately, withheld from those involved in the patient's care (especially general practitioners (GPs)). Additional difficulties were exposed when doctors were asked by insurers to comment on patients' lifestyles. This highlighted the wider problems of GPs being at the centre of the patient's health care delivery, receiving information in confidence, and also being asked to act as the agent of another master. The conflicts led to a helpful reassessment of roles, priorities and procedures. This anticipated similar problems in screening for genetic disorders.

For clinicians, the most substantial tension has been in the potential or perceived conflict between the duty to the individual and the duty to protect others. How far should a doctor go in attempting to protect others from HIV risk from his patient? Many clinicians are very uncomfortable with knowing that an HIV-positive patient is continuing to have unsafe sex with a person whom the patient is unwilling to inform. After attempting to influence the patient's behaviour or willingness to disclose his HIV status, the clinician may be left either unable to act further because of confidentiality, or feeling obliged to breach confidentiality to protect the third party. General Medical Council guidance allows either, so long as the clinician is able to justify his actions. Each case has to be judged on its particulars.

There is a real hazard if the clinician starts to act beyond the compass of his role with his patient. If patients perceive that a doctor will breach confidentiality to protect others, such information will no longer be forthcoming. Bitter experience has shown how patients react if their clinicians seem more concerned about others than about them. Such breaches will also affect the wider public perception of what can safely be revealed to doctors. Arguably the person most able to influence the patient for the wider benefit would not be told, and thus would be unable to exert any influence to protect others.

\section{ADVOCACY AND ACTIVISM}

The substantial development of patient advocacy had its origins in the problems of stigma and alienation felt by affected groups, reflecting a human rights context. An emerging solidarity, reinforced by the cumulative personal losses, soon led to action to protect each other through prevention programmes, based on peer-based education and influence. These were impressively relevant, focused and unfettered by the constraints limiting official campaigns. Issues of access to care and to information followed, leading to treatment activism, driven by a strong desire for more satisfactory outcomes.

Anger, mainly derived from the consequences of the disease, was not infrequently directed at clinicians. This was sad and painful to witness, since the clinicians involved in AIDS work were arguably among the earliest activists. It was also increasingly directed at the pharmaceutical industry, which was perceived as lacking interest, or only interested in profit. Much misunderstanding arose, and there were uncomfortable years when the activists took up extremist positions and actions which tended to alienate their allies, natural or necessary. Gradually the process has become more interactive than antagonistic, and very beneficial partnerships have emerged.

Concerns about the conduct of clinical trials and delays in drug availability and licensure became a public expression of the ethics of emergency. Strong representations were made for parallel availability of investigational agents for those with advancing and severe disease, who wanted an opportunity to benefit, even if knowledge about safety and efficacy was limited. Affected communities were starting to determine and extend limits on access to new drugs, not waiting for the paternalistic judgments of triallists, regulatory agencies or research ethics committees. There was considerable resentment and misunderstanding about the use of placebos, randomisation and intention-to-treat analysis, which were seen as disempowering, arbitrary and irrational. Such plausible views showed up the failure of clinicians and scientists to explain such methodologies and their rationale.

However, soon activists became formally involved in trial design and implementation, leading to substantial changes in the way trials were done, with a greater sensitivity to patient concerns. Activists rapidly gained a sophisticated understanding of trial design and process. The demonisation of process was replaced by its careful assessment and refinement, ensuring that studies were owned by the affected community, extending empowerment to clinical research. As with so much else in HIV/AIDS, these advances have gone on to inform the approaches to other diseases. 
An important lesson for clinicians and activists alike was the distinction between patient advocacy as a group phenomenon and the views, aspirations and expectations of individuals as patients. Patient voices expressed things, not only less confrontationally, but often with a different content too. Clinicians needed to ensure that all these voices, collective and personal, were folded into the treatment approach.

This issue was well illustrated at an advocacy group meeting about the Concorde trial (zidovudine monotherapy $\mathrm{v}$ placebo in asymptomatic HIV infection). A speaker who had vigorously rejected not only the trial and the use of placebos, but also zidovudine itself, asked me (as a patient): "Should I start zidovudine now?", expecting the answer yes! His contrasting platform oratory and private question were explained as being the polemic means to shift attitudes and his personal perspective, respectively. $\mathrm{He}$ saw no real conflict.

This highlights how important it is not to make assumptions about what patients want. It also reinforces the need to distance oneself from reactions to the attacks on clinicians by activists, when dealing with patients. This returns us to the issue of respecting patient autonomy. It underscores that this applies just as much to patients' autonomy with respect to their social groups, as it does to their autonomy with respect to clinicians.

\section{The impact of aids on medical ethics -2} ROGER HIGGS

If in Western Europe in the early eighties we were really beginning to see the positive effects of more tolerance towards minorities, the arrival of a devastating infectious disease, particularly affecting sections of the male gay and immigrant African communities might in retrospect seem more than a cruel blow. At the time, unenthusiastic greetings, banner headlines and abuse (or worse) through the letter box made it feel as if the moral clock was being decisively put back. No one needed to teach about stigma on sociology courses any more. Even the welcome handshake of a beautiful Princess could barely lighten the scene. In Britain, primary care shared in the atmosphere of rejection: just when the skills of a personal physician should have been most effective and beneficial, (what else was on offer?), general practice was seen by some as inadequate, "leaky" or homophobic and so not to be trusted by minority communities under siege.

But although the threats have not by any means passed, it is now possible to look back on positives and some moral progress. Primary care, though often reduced to the status of prompt or second citizen in the drama, has learned to improve its act in ways which might otherwise not have hap- pened. The effects might be practical, even pragmatic but are not the worse for that: it is in day-to-day ordinary business that primary care must pass or fail its moral audit. There have been effects in the encounter both at reception and in the office. In the former, questions like: "What's it for?" and discussion amongst staff in a hoarse audible whisper are no longer acceptable. In the latter, the requirement to discuss orientation or behaviour has meant that doctor and patient have jointly had to grasp the nettle (and bear the histamine response). What goes in the notes is no longer a doctor's issue only or something which goes by default. It is often discussed, queried and modified. Patients have begun to be warned about what may be difficult to write. Barriers have been raised against intrusive but narrowly legitimate questions from outsiders. The safety of notes has become an everyday issue.

Sadly, this has been too late for many, especially in the gay community, who have lost their trust in the system and have remained linked to GPs only for "things which don't matter", as one patient recently put it to me. The benefits may have been felt mostly by others, who were originally less organised or articulate. But AIDS has not, as some would maintain, altered the answers to questions in medical ethics, it has just clarified or sharpened the issues. The conundrums still remain, such as to how to run a personal confidential service for individuals while respecting the needs of the family group (a difficult skill but vital), or while offering access to insurance companies for information (impossible in this writer's view). But at least we are clearer: until insurance companies in general are refused access, it has to be "don't tell me about all your boyfriends", or "don't tell the mortgage company about me". Every game has rules: it is not cynical but vital for them to be revealed. Only after that can we all debate and agree to change them.

Perhaps this greater openness has been one of the gifts forced on us by AIDS, mediated through the gay community. One of the others would be a completely new view of friendship and its power. We are still nowhere near understanding this in our society, which is obsessed with the importance of sexual contact. But other relationships may be central to the good life: the miserable child, rejected in the playground, says it all. We may need partners, but we desperately need friends. What friendship can offer, in terms of range and depth has been given a new dimension in this epidemic. When curative medicine had little to offer, where society could give no legal protection, where the palliatives of religion had become threadbare, the mutual support of friends became 
the only and most potent of medicines. In many cases it really created a new resource. It has not been lost on those of us who serve and observe. Not before time.

\section{The impact of AIDS on medical ethics -3 KENNETH M BOYD}

The impact of AIDS on medical ethics perhaps can be compared to the impact of war on medicine itself. Applied to medicine, military metaphors are often misleading; they belie its sheer everydayness. But in wartime, everydayness is seen in a different light, new solutions are found to old problems, and few wars have ended without some contribution having been made to medical progress. The arrival of AIDS had similar effects on medical ethics. Few clinicians were untouched by it; nor, as in all modern wars, was the civilian population.

Some of the most significant effects of AIDS on medical ethics are illustrated by what Professor Pinching writes about empowerment, confidentiality, and advocacy and activism. His reflections, although recollected in tranquillity, retain the sharp tang of dispatches from the front, and their authority. But not everyone, not all clinicians and certainly not all civilians, were as closely engaged. And wars end, and some of their lessons are not learnt, or learnt in the wrong way, and that is sometimes why new wars begin. From the perspective of those who were less closely engaged, how deep and how lasting has been the impact of AIDS on medical ethics?

A mere decade or so since the pandemic became public knowledge, it is probably too soon to say. The immediate shock effects, particularly in the late eighties, however, are a matter of record. Doctors trained in the post-antibiotic era rediscovered that medical practice can never be free of fatal risk; many of their post-pill contemporaries learned a similar lesson about sex, and about intravenous drug use. Gay pride, or at least self respect, found that it often had no option but to come out, and went on to force the pace of ethical debates about consent, confidentiality, clinical trials, screening and testing, euthanasia and living wills. Well-defended moral positions such as that of the Roman Catholic Church on contraception were attacked from unexpected new angles; the condom as a preventative gained new respectability as a prophylactic; and the word itself (admitted to the Oxford English Dictionary only in the 1970s [c 1760, origin unknown]) entered polite as well as vulgar conversation.

Shock effects shake people, and assumptions about the inevitability of medical and social progress - formed in the war-torn forties and lean fifties as well as the exuberant sixties - were shaken or at least stirred by the crunching AIDS iceberg launched across television screens by wellintentioned health educationists. The glasnost generation, just beginning to feel less apprehensive about a nuclear holocaust, saw a new and intimidating obstacle blocking the route to a return to normalcy. In the mid to late 1980 s, when the proportion of the population already infected but asymptomatic was unknown, and the likely progress of the pandemic unpredictable, the longdead metaphors of plague and pestilence were resurrected, and proliferated in the media, greatly enlarging the ranks of the worried-well and the rhetorical resources of advocates of "a return to traditional morality".

Not everyone was convinced by the rhetoric or persuaded by the propaganda. The sceptics included not only hearties and hedonists, but also determined defenders of civil rights, who opposed demands for compulsory testing of patients and other vulnerable groups, or for people with HIV to be quarantined. While the latter at least may never have been a live political option, other forms of discrimination, from health care workers refusing to treat AIDS patients, to calls for HIV to be made a notifiable disease, symptomised the panic caused in some quarters in the early days of the pandemic.

That this can now be called a panic, and demands for draconian measures seen as extreme over-reactions, may be one of the more lasting legacies of AIDS. Since the eighties, medical and media health warnings about new or rejuvenated diseases have become increasingly common. But so too has the tendency within informed public opinion to think that, as with HIV, we should wait and see what happens, before assuming that necrotising fasciitis, or Chinese chicken flu, or new variant CJD, is the late twentieth century equivalent to the Black Death. That is not, of course, to say that they, or more probably some other virulent infectious agent waiting in the wings, will not be. But if that happens, and society waits too long to put effective preventive measures in place, part of the reason for the delay may be attributable to HIV-borne scepticism about medical and media health scares.

Another legacy of AIDS that seems likely to last, may be less equivocal. People with HIV were not the first patients, advocates and activists pressing for a shift from paternalism to partnership in doctor-patient relationships. Women in childbirth, parents of sick children, and patients with a variety of conditions requiring prolonged contact with hospital staff, had already started down that path, often with medical encouragement. But as Professor Pinching describes, many 
people with HIV wished to go further and faster, forcing their clinicians to think through the ethical issues until they were able to articulate a "joinedup" rationale for what increasingly made practical sense to them. Other clinicians were less convinced of the need for change. But needing to learn rapidly about HIV, they heard at the same time from AIDS specialists their message about empowerment and partnership - rather as they had heard not dissimilar messages earlier from palliative care specialists. Not coincidentally perhaps, these messages began to sound increasingly credible as clinical judgment was increasingly questioned by compensation lawyers and market-oriented politicians. People with HIV and their physicians, clearly, were far from the only agents responsible for this shift of emphasis in medical ethics. But by being there and articulate at a critical moment, they played a decisive part in it.

What may yet prove the most lasting legacy of AIDS seems at first sight beyond the sphere of medical ethics. The implications of HIV for the public health, especially while the extent and spread of the infection remained unpredictable, mandated an unprecedented degree of explicitness in government as well as media discussions about the use and abuse of drugs, and safer and more risky sexual practices. Battles were fought about just how overtly and often such issues could be raised by schoolteachers and or health educationists, but as long as a sufficient proportion of the population continued to fear that they were all in this together, openness mostly won out. One consequence of this was that traditional silence about homosexuality was broken, and longstanding prohibitions against its expression seriously questioned, even in naturally conservative organisations such as the mainstream churches. Today, homosexuality is increasingly seen as a normal, if minority, sexual orientation, so much so that it is difficult to see what would reverse this major shift in social attitudes.

The impact of AIDS, of course, was not the only cause of this shift, but again it was perhaps the decisive one. Part of what made it decisive, was that attempts to stigmatise homosexuals by branding HIV infection as a "gay plague" had such a signally unsuccessful effect on public opinion; and part of the reason for that perhaps, was that public opinion took its lead from the ethical tone, not universal but increasingly dominant in medicine, of non-judgmentalism. At a time when many clinicians were moving towards greater empowerment of and partnership with their patients, a growing mood in public opinion was moving towards a more therapeutic attitude to life and its problems. In a different context, greater openness and a more therapeutic attitude also led many people to question the wisdom of a prohibitionist public policy on drug use.

It would, however, be risky to push this argument too far. Greater openness and a more therapeutic attitude coexist uneasily with populist nostalgia and the culture of blame. The future moreover is another country - literally so from a parochial perspective that speaks of the impact of AIDS in the past tense. The war, if the metaphor holds, is far from over in Africa and Asia, where its impact already is vastly more devastating in population terms. But populations are made up of individual lives, and as the philosopher Ortega y Gasset observed: "Every life is, more or less, a ruin among whose debris we have to discover what the person ought to have been". ${ }^{1}$ Perhaps it is only when we are able, unflinchingly, to face up to that harsh but ultimately hopeful truth - about all lives, our own included - that the true impact of AIDS in our time becomes clearer. Then too, we may also begin to understand what another philosopher, Paul Ricoeur, meant when he wrote: "We tell stories because in the last analysis human lives need and merit being narrated. This remark takes on its full force when we refer to the necessity to save the history of the defeated and the lost."2

Anthony $\mathcal{F}$ Pinching is Louis Freedman Professor of Immunology and Fellow, Department of Human Science and Medical Ethics, St Bartholomew's and The Royal London School of Medicine and Dentistry, Queen Mary \& Westfield College, West Smithfield London EC1A 7BE. Roger Higgs is Professor of General Practice and Primary Care, Guy's, King's and St Thomas' School of Medicine, King's College London, Department of General Practice and Primary Care, 10, Cutcombe Road, London SE5 9RF. Kenneth M Boyd is Senior Lecturer in Medical Ethics, Edinburgh University Medical School and Research Director, Institute of Medical Ethics.

\section{References}

1 y Gasset O. The dehumanization of art. New York: Doubleday,

2 Ricoeur P. Time and narrative [vol 1]. Chicago: Chicago Ricoeur P. Time and
University Press, 1984. 